\title{
An Iteration to a Common Point of Solution of Variational Inequality and Fixed Point-Problems in Banach Spaces
}

\author{
H. Zegeye ${ }^{1}$ and N. Shahzad ${ }^{2}$ \\ ${ }^{1}$ Department of Mathematics, University of Botswana, Private Bag 00704, Gaborone, Botswana \\ ${ }^{2}$ Department of Mathematics, King Abdulaziz University, P.O. Box 80203, Jeddah 21589, Saudi Arabia
}

Correspondence should be addressed to N. Shahzad, nshahzad@kau.edu.sa

Received 24 February 2012; Accepted 5 April 2012

Academic Editor: Yonghong Yao

Copyright (c) 2012 H. Zegeye and N. Shahzad. This is an open access article distributed under the Creative Commons Attribution License, which permits unrestricted use, distribution, and reproduction in any medium, provided the original work is properly cited.

We introduce an iterative process which converges strongly to a common point of solution of variational inequality problem for a monotone mapping and fixed point of uniformly Lipschitzian relatively asymptotically nonexpansive mapping in Banach spaces. As a consequence, we provide a scheme that converges strongly to a common zero of finite family of monotone mappings under suitable conditions. Our theorems improve and unify most of the results that have been proved for this important class of nonlinear operators.

\section{Introduction}

Let $E$ be a smooth Banach space. Throughout this paper, we denote by $\phi: E \times E \rightarrow \mathbb{R}$ the function defined by

$$
\phi(y, x)=\|y\|^{2}-2\langle y, J x\rangle+\|x\|^{2}, \quad \text { for } x, y \in E,
$$

which was studied by Alber [1], Kamimura and Takahashi [2], and Reich [3], where $J$ is the normalized duality mapping from $E$ to $2^{E^{*}}$ defined by

$$
J x:=\left\{f^{*} \in E^{*}:\left\langle x, f^{*}\right\rangle=\|x\|^{2}=\left\|f^{*}\right\|^{2}\right\},
$$


where $\langle\cdot, \cdot\rangle$ denotes the duality pairing. It is well known that if $E$ is smooth, then $J$ is singlevalued, and, if $E$ has uniformly Gâteaux differentiable norm, then $J$ is uniformly continuous on bounded subsets of $E$. Moreover, if $E$ is a reflexive and strictly convex Banach space with a strictly convex dual, then $J^{-1}$ is single valued, one-to-one, surjective, and it is the duality mapping from $E^{*}$ into $E$, and thus $J J^{-1}=I_{E^{*}}$ and $J^{-1} J=I_{E}$ (see [4]).

It is obvious from the definition of the function $\phi$ that

$$
(\|x\|-\|y\|)^{2} \leq \phi(x, y) \leq(\|x\|+\|y\|)^{2} \quad \text { for } x, y \in E,
$$

and, in a Hilbert space $H,(1.1)$ reduces to $\phi(x, y)=\|x-y\|^{2}$, for $x, y \in H$.

Let $E$ be a reflexive, strictly convex, and smooth Banach space, and let $C$ be a nonempty closed and convex subset of $E$. The generalized projection mapping, introduced by Alber [1], is a mapping $\Pi_{C}: E \rightarrow C$ that assigns an arbitrary point $x \in E$ to the minimizer, $\bar{x}$, of $\phi(\cdot, x)$ over $C$, that is, $\Pi_{C} x=\bar{x}$, where $\bar{x}$ is the solution to the minimization problem

$$
\phi(\bar{x}, x)=\min \{\phi(y, x), y \in C\}
$$

Let $E$ be a real Banach space with dual $E^{*}$. A mapping $A: D(A) \subset E \rightarrow E^{*}$ is said to be monotone if, for each $x, y \in D(A)$, the following inequality holds:

$$
\langle x-y, A x-A y\rangle \geq 0
$$

$A$ is said to be $\gamma$-inverse strongly monotone if there exists positive real number $\gamma$ such that

$$
\langle x-y, A x-A y\rangle \geq \gamma\|A x-A y\|^{2}, \quad \forall x, y \in K .
$$

If $A$ is $\gamma$-inverse strongly monotone, then it is Lipschitz continuous with constant $1 / \gamma$, that is, $\|A x-A y\| \leq(1 / \gamma)\|x-y\|$, for all $x, y \in D(A)$, and it is called strongly monotone if there exists $k>0$ such that, for all $x, y \in D(A)$,

$$
\langle x-y, A x-A y\rangle \geq k\|x-y\|^{2}
$$

Clearly, the class of monotone mappings include the class of strongly monotone and $\gamma$-inverse strongly monotone mappings.

Suppose that $A$ is monotone mapping from $C$ into $E^{*}$. The variational inequality problem is formulated as finding a point $u \in C$ such that $\langle v-u, A u\rangle \geq 0$, for all $v \in C$. The set of solutions of the variational inequality problems is denoted by $\operatorname{VI}(C, A)$.

The notion of monotone mappings was introduced by Zarantonello [5], Minty [6], and Kacurovskii [7] in Hilbert spaces. Monotonicity conditions in the context of variational methods for nonlinear operator equations were also used by Vainberg and Kachurovisky [8]. Variational inequalities were initially studied by Stampacchia $[9,10]$ and ever since have been 
widely studied in general Banach spaces (see, e.g., [2, 11-13]). Such a problem is connected with the convex minimization problem, the complementarity problem, the problem of finding point $u \in C$ satisfying $0 \in A u$.

If $E=H$, a Hilbert space, one method of solving a point $u \in \operatorname{VI}(C, A)$ is the projection algorithm which starts with any point $x_{1}=x \in C$ and updates iteratively as $x_{n+1}$ according to the formula

$$
x_{n+1}=P_{C}\left(x_{n}-\alpha_{n} A x_{n}\right), \quad \text { for any } n \geq 1,
$$

where $P_{C}$ is the metric projection from $H$ onto $C$ and $\left\{\alpha_{n}\right\}$ is a sequence of positive real numbers. In the case that $A$ is $\gamma$-inverse strongly monotone, Iiduka et al. [14] proved that the sequence $\left\{x_{n}\right\}$ generated by (3.35) converges weakly to some element of $\operatorname{VI}(C, A)$.

In the case that $E$ is a 2-uniformly convex and uniformly smooth Banach space, Iiduka and Takahashi [15] introduced the following iteration scheme for finding a solution of the variational inequality problem for an inverse strongly monotone operator $A$ :

$$
x_{n+1}=\Pi_{C} J^{-1}\left(J x_{n}-\alpha_{n} A x_{n}\right), \quad \text { for any } n \geq 1,
$$

where $\Pi_{C}$ is the generalized projection from $E$ onto $C, J$ is the normalized duality mapping from $E$ into $E^{*}$, and $\left\{\alpha_{n}\right\}$ is a sequence of positive real numbers. They proved that the sequence $\left\{x_{n}\right\}$ generated by (1.9) converges weakly to some element of $\mathrm{VI}(C, A)$ provided that $A$ satisfies $\|A x\| \leq\|A x-A p\|$, for $x \in C$ and $p \in \operatorname{VI}(C, A)$.

It is worth to mention that the convergence is weak convergence.

To obtain strong convergence, when $E=H$, a Hilbert space and $A$ is $\gamma$-inverse strongly monotone; Iiduka et al. [14] studied the following iterative scheme:

$$
\begin{gathered}
x_{0} \in C, \text { chosen arbitrary, } \\
y_{n}=P_{C}\left(x_{n}-\alpha_{n} A x_{n}\right), \\
C_{n}=\left\{z \in C:\left\|y_{n}-z\right\| \leq\left\|x_{n}-z\right\|\right\}, \\
Q_{n}=\left\{z \in C:\left\langle x_{n}-z, x_{0}-x_{n}\right\rangle \geq 0\right\}, \\
x_{n+1}=P_{C_{n} \cap Q_{n}}\left(x_{0}\right), \quad n \geq 1, \text { for } n \geq 1,
\end{gathered}
$$

where $\left\{\alpha_{n}\right\}$ is a sequence in $[0,2 \gamma]$. They proved that the sequence $\left\{x_{n}\right\}$ generated by $(1.10)$ converges strongly to $P_{\mathrm{VI}(C, A)}\left(x_{0}\right)$, where $P_{\mathrm{VI}(C, A)}$ is the metric projection from $H$ onto $\operatorname{VI}(C, A)$ provided that $A$ satisfies $\|A x\| \leq\|A x-A p\|$, for $x \in C$ and $p \in \operatorname{VI}(C, A)$.

In the case that $E$ is 2-uniformly convex and uniformly smooth Banach space, liduka and Takahashi [11] studied the following iterative scheme for a variational inequality 
problem for $\gamma$-inverse strongly monotone mapping:

$$
\begin{gathered}
x_{0} \in K, \text { chosen arbitrary, } \\
y_{n}=\Pi_{C} J^{-1}\left(J x_{n}-\alpha_{n} A x_{n}\right), \\
C_{n}=\left\{z \in E: \phi\left(z, y_{n}\right) \leq \phi\left(z, x_{n}\right)\right\}, \\
Q_{n}=\left\{z \in E:\left\langle x_{n}-z, J x_{0}-J x_{n}\right\rangle \geq 0\right\}, \\
x_{n+1}=\Pi_{C_{n} \cap Q_{n}}\left(x_{0}\right), n \geq 1, \quad \text { for } n \geq 1,
\end{gathered}
$$

where $\Pi_{C_{n} \cap Q_{n}}$ is the generalized projection from $E$ onto $C_{n} \cap Q_{n}, J$ is the normalized duality mapping from $E$ into $E^{*}$, and $\left\{\alpha_{n}\right\}$ is a positive real sequence satisfying certain condition. Then, they proved that the sequence $\left\{x_{n}\right\}$ converges strongly to an element of $\operatorname{VI}(C, A)$ provided that $\operatorname{VI}(C, A) \neq \emptyset$ and $A$ satisfies $\|A x\| \leq\|A x-A p\|$ for all $x \in C$ and $p \in \operatorname{VI}(C, A)$.

Remark 1.1. We remark that the computation of $x_{n+1}$ in Algorithms (1.10) and (1.11) is not simple because of the involvement of computation of $C_{n+1}$ from $C_{n}$ and $Q_{n}$ for each $n \geq 1$.

Let $T$ be a mapping from $C$ into itself. We denote by $F(T)$ the fixed points set of $T$. A point $p$ in $C$ is said to be an asymptotic fixed point of $T$ (see [3]) if $C$ contains a sequence $\left\{x_{n}\right\}$ which converges weakly to $p$ such that $\lim _{n \rightarrow \infty}\left\|x_{n}-T x_{n}\right\|=0$. The set of asymptotic fixed points of $T$ will be denoted by $\widehat{F}(T)$. A mapping $T$ from $C$ into itself is said to be nonexpansive if $\|T x-T y\| \leq\|x-y\|$ for each $x, y \in C$ and is called relatively nonexpansive if (R1) $F(T) \neq \emptyset$; (R2) $\phi(p, T x) \leq \phi(p, x)$ for $x \in C$ and (R3) $F(T)=\widehat{F}(T)$. $T$ is called relatively quasi-nonexpansive if $F(T) \neq \emptyset$ and $\phi(p, T x) \leq \phi(p, x)$ for all $x \in C$, and $p \in F(T)$.

A mapping $T$ from $C$ into itself is said to be asymptotically nonexpansive if there exists $\left\{k_{n}\right\} \subset[1, \infty)$ such that $k_{n} \rightarrow 1$ and $\left\|T^{n} x-T^{n} y\right\| \leq k_{n}\|x-y\|$ for each $x, y \in C$ and is called relatively asymptotically nonexpansive if there exists $\left\{k_{n}\right\} \subset[1, \infty)$ such that $(\mathrm{N} 1) F(T) \neq \emptyset ;(\mathrm{N} 2)$ $\phi\left(p, T^{n} x\right) \leq k_{n} \phi(p, x)$ for $x \in C$ and $p \in F(T)$, and (N3) $F(T)=\widehat{F}(T)$, where $k_{n} \rightarrow 1$ as $n \rightarrow \infty$. A-self mapping on $C$ is called uniformly L-Lipschitzian if there exists $L>0$ such that $\left\|T^{n} x-T^{n} y\right\| \leq L\|x-y\|$ for all $x, y \in C$. $T$ is called closed if $x_{n} \rightarrow x$ and $T x_{n} \rightarrow y$, then $T x=y$.

Clearly, we note that the class of relatively nonexpansive mappings is contained in a class of relatively asymptotically nonexpansive mappings but the converse is not true. Now, we give an example of relatively asymptotically nonexpansive mapping which is not relatively nonexpansive.

Example 1.2 (see [16]). Let $X=l^{p}$, where $1<p<\infty$, and $C=\left\{x=\left(x_{1}, x_{2}, \ldots\right) \in X ; x_{n} \geq\right.$ $0\}$. Then $C$ is closed and convex subset of $X$. Note that $C$ is not bounded. Obviously, $X$ is uniformly convex and uniformly smooth. Let $\left\{\lambda_{n}\right\}$ and $\left\{\bar{\lambda}_{n}\right\}$ be sequences of real numbers satisfying the following properties:

(i) $0<\lambda_{n}<1, \bar{\lambda}_{n}>1, \lambda_{n} \uparrow 1$, and $\bar{\lambda}_{n} \downarrow 1$,

(ii) $\lambda_{n+1} \bar{\lambda}_{n}=1$ and $\lambda_{j+1} \bar{\lambda}_{n+j}<1$ for all $n$ and $j$ (e.g., $\left.\lambda_{n}=1-1 /(n+1), \bar{\lambda}_{n}=1+1 /(n+1)\right)$. Then, the map $T: C \rightarrow C$ defined by

$$
T x:=\left(0, \bar{\lambda}_{1}\left|\sin x_{1}\right|, \lambda_{2} x_{2}, \bar{\lambda}_{2} x_{3}, \lambda_{3} x_{4}, \bar{\lambda}_{3} x_{5}, \ldots\right),
$$


for all $x=\left(x_{1}, x_{2}, \ldots\right) \in C$, is uniformly Lipschitzian which is relatively asymptotically nonexpansive but not relatively nonexpansive (see [16] for the details). Note also that $F(T)=\{0\}$.

In 2005, Matsushita and Takahashi [17] proposed the following hybrid iteration method with generalized projection for relatively nonexpansive mapping $T$ in a Banach space E:

$$
\begin{gathered}
x_{0} \in C \text {, chosen arbitrary, } \\
y_{n}=J^{-1}\left(\alpha_{n} J x_{n}+\left(1-\alpha_{n}\right) J T x_{n}\right), \\
C_{n}=\left\{z \in C: \phi\left(z, y_{n}\right) \leq \phi\left(z, x_{n}\right)\right\}, \\
Q_{n}=\left\{z \in C ;\left\langle x_{n}-z, J x_{0}-J x_{n}\right\rangle \geq 0\right\}, \\
x_{n+1}=\Pi_{C_{n} \cap Q_{n}}\left(x_{0}\right), \quad n \geq 1 .
\end{gathered}
$$

They proved that, if the sequence $\left\{\alpha_{n}\right\}$ is bounded above from one, then the sequence $\left\{x_{n}\right\}$ generated by (1.13) converges strongly to $\Pi_{F(T)} x_{0}$.

Recently, many authors have considered the problem of finding a common element of the fixed-point set of relatively nonexpansive mapping and the solution set of variational inequality problem for $\gamma$-inverse monotone mapping (see, e.g., $[12,13,18-20]$ ).

In [21], Iiduka and Takahashi studied the following iterative scheme for a common point of solution of a variational inequality problem for $\gamma$-inverse strongly monotone mapping $A$ and fixed point of nonexpansive mapping $T$ in a Hilbert space $H$ :

$$
\begin{gathered}
x_{1}=x \in C, \\
x_{n+1}=\alpha_{n} x+\left(1-\alpha_{n}\right) S P_{C}\left(x_{n}-\lambda_{n} A x_{n}\right), \quad n \geq 1,
\end{gathered}
$$

where $\left\{\alpha_{n}\right\}$ is sequences satisfying certain condition. They proved that the sequence $\left\{x_{n}\right\}$ converges strongly to an element of $F:=F(S) \cap \operatorname{VI}(C, A)$ provided that $F \neq \emptyset$.

In the case that $E$ is a Banach space more general than Hilbert spaces, Zegeye et al. [12] studied the following iterative scheme for a common point of solution of a variational inequality problem for $\gamma$-inverse strongly monotone mapping $A$ and fixed point of a closed relatively quasi-nonexpansive mapping $T$ in a 2-uniformly convex and uniformly smooth Banach space $E$ :

$$
\begin{gathered}
C_{1}=C, \text { chosen arbitrary, } \\
z_{n}=\Pi_{C}\left(x_{n}-\lambda_{n} A x_{n}\right), \\
y_{n}=J^{-1}\left(\beta J x_{n}+(1-\beta) J T z_{n}\right), \\
C_{n+1}=\left\{z \in C_{n}: \phi\left(z, y_{n}\right) \leq \phi\left(z, x_{n}\right)\right\}, \\
x_{n+1}=\Pi_{C_{n+1}}\left(x_{0}\right), \quad n \geq 1,
\end{gathered}
$$

where $\left\{\lambda_{n}\right\}$ is sequences satisfying certain condition. They proved that the sequence $\left\{x_{n}\right\}$ converges strongly to an element of $F:=F(S) \cap \operatorname{VI}(C, A) \neq \emptyset$ provided that $F \neq \emptyset$ and $A$ satisfies $\|A x\| \leq\|A x-A p\|$ for all $x \in C$ and $p \in F$.

Furthermore, Zegeye and Shahzad [22] studied the following iterative scheme for common point of solution of a variational inequality problem for $\gamma$-inverse strongly 
monotone mapping $A$ and fixed point of a relatively asymptotically nonexpansive mapping on a closed convex and bounded set $C$ which is a subset of a real Hilbert space $H$ :

$$
\begin{gathered}
C_{1}=C \text {, chosen arbitrary, } \\
z_{n}=P_{C}\left(x_{n}-\lambda_{n} A x_{n}\right), \\
y_{n}=\alpha_{n} x_{n}+\left(1-\alpha_{n}\right) S^{n} z_{n}, \\
C_{n+1}=\left\{z \in C_{n}:\left\|z-u_{n}\right\|^{2} \leq\left\|z-x_{n}\right\|^{2}+\theta_{n}\right\}, \\
x_{n+1}=P_{C_{n+1}}\left(x_{0}\right), \quad n \geq 1,
\end{gathered}
$$

where $P_{C_{n}}$ is the metric projection from $H$ into $C_{n}$ and $\theta_{n}=\left(1-\alpha_{n}\right)\left(k_{n}^{2}-1\right)(\operatorname{diam}(C))^{2}$ and $\left\{\alpha_{n}\right\},\left\{\lambda_{n}\right\}$ are sequences satisfying certain condition. Then, they proved that the sequence $\left\{x_{n}\right\}$ converges strongly to an element of $F:=F(S) \cap \operatorname{VI}(C, A) \neq \emptyset$ provided that $F \neq \emptyset$ and $A$ satisfies $\|A x\| \leq\|A x-A p\|$ for all $x \in C$ and $p \in F$.

Remark 1.3. We again remark that the computation of $x_{n+1}$ in Algorithms (1.13), (1.15), and (1.16) is not simple because of the involvement of computation of $C_{n+1}$ from $C_{n}$ for each $n \geq 1$.

It is our purpose in this paper to introduce an iterative scheme $\left\{x_{n}\right\}$ which converges strongly to a common point of solution of variational inequality problem for a monotone operator $A: C \rightarrow E^{*}$ satisfying appropriate conditions, for some nonempty closed convex subset $C$ of a Banach space $E$ and fixed points of uniformly $L$-Lipschitzian relatively asymptotically nonexpansive mapping in Banach spaces. As a consequence, we provide a scheme which converges strongly to a common zero of finite family of monotone mappings. Our scheme does not involve computation of $C_{n+1}$ from $C_{n}$ or $Q_{n}$, for each $n \geq 1$. Our theorems improve and unify most of the results that have been proved for this important class of nonlinear operators.

\section{Preliminaries}

Let $E$ be a normed linear space with $\operatorname{dim} E \geq 2$. The modulus of smoothness of $E$ is the function $\rho_{E}:[0, \infty) \rightarrow[0, \infty)$ defined by

$$
\rho_{E}(\tau):=\sup \left\{\frac{\|x+y\|+\|x-y\|}{2}-1:\|x\|=1 ;\|y\|=\tau\right\}
$$

The space $E$ is said to be smooth if $\rho_{E}(\tau)>0$, for all $\tau>0$, and $E$ is called uniformly smooth if and only if $\lim _{t \rightarrow 0^{+}}\left(\rho_{E}(t) / t\right)=0$.

The modulus of convexity of $E$ is the function $\delta_{E}:(0,2] \rightarrow[0,1]$ defined by

$$
\delta_{E}(\epsilon):=\inf \left\{1-\left\|\frac{x+y}{2}\right\|:\|x\|=\|y\|=1 ; \epsilon=\|x-y\|\right\}
$$

$E$ is called uniformly convex if and only if $\delta_{E}(\epsilon)>0$, for every $\epsilon \in(0,2]$. 
In the sequel, we will need the following results.

Lemma 2.1 (see [23]). Let $C$ be a nonempty closed and convex subset of a real reflexive, strictly convex, and smooth Banach space $E$. If $A: C \rightarrow E^{*}$ is continuous monotone mapping, then $\operatorname{VI}(C, A)$ is closed and convex.

Lemma 2.2. Let $C$ be a closed convex subset of a uniformly convex and smooth Banach space $E$, and let $S$ be continuous relatively asymptotically nonexpansive mapping from $C$ into itself. Then, $F(S)$ is closed and convex.

Lemma 2.3 (see [1]). Let $K$ be a nonempty closed and convex subset of a real reflexive, strictly convex, and smooth Banach space $E$, and let $x \in E$. Then, for all $y \in K$,

$$
\phi\left(y, \Pi_{K} x\right)+\phi\left(\Pi_{K} x, x\right) \leq \phi(y, x) .
$$

Lemma 2.4 (see [2]). Let $E$ be a real smooth and uniformly convex Banach space, and let $\left\{x_{n}\right\}$ and $\left\{y_{n}\right\}$ be two sequences of $E$. If either $\left\{x_{n}\right\}$ or $\left\{y_{n}\right\}$ is bounded and $\phi\left(x_{n}, y_{n}\right) \rightarrow 0$ as $n \rightarrow \infty$, then $x_{n}-y_{n} \rightarrow 0$, as $n \rightarrow \infty$.

We make use of the function $V: E \times E^{*} \rightarrow \mathbb{R}$ defined by

$$
V\left(x, x^{*}\right)=\|x\|^{2}-2\left\langle x, x^{*}\right\rangle+\|x\|^{2}, \quad \forall x \in E, x^{*} \in E,
$$

studied by Alber [1]. That is, $V(x, y)=\phi\left(x, J^{-1} x^{*}\right)$ for all $x \in E$ and $x^{*} \in E^{*}$. We know the following lemma.

Lemma 2.5 (see [1]). Let $E$ be reflexive strictly convex and smooth Banach space with $E^{*}$ as its dual. Then,

$$
V\left(x, x^{*}\right)+2\left\langle J^{-1} x^{*}-x, y^{*}\right\rangle \leq V\left(x, x^{*}+y^{*}\right),
$$

for all $x \in E$ and $x^{*}, y^{*} \in E^{*}$.

Lemma 2.6 (see [1]). Let $C$ be a convex subset of a real smooth Banach space E. Let $x \in E$. Then $x_{0}=\Pi_{C} x$ if and only if

$$
\left\langle z-x_{0}, J x-J x_{0}\right\rangle \leq 0, \quad \forall z \in C
$$

Lemma 2.7 (see [12]). Let E be a uniformly convex Banach space and $B_{R}(0)$ a closed ball of $E$. Then, there exists a continuous strictly increasing convex function $g:[0, \infty) \rightarrow[0, \infty)$ with $g(0)=0$ such that

$$
\left\|\alpha_{1} x_{1}+\alpha_{2} x_{2}+\alpha_{3} x_{3}\right\|^{2} \leq \alpha_{i}\left\|x_{1}\right\|^{2}+\alpha_{2}\left\|x_{2}\right\|^{2}+\alpha_{3}\left\|x_{3}\right\|^{2}-\alpha_{i} \alpha_{j} g\left(\left\|x_{i}-x_{j}\right\|\right)
$$

for $\alpha_{i} \in(0,1)$ such that $\alpha_{1}+\alpha_{2}+\alpha_{3}=1$ and $x_{i} \in B_{R}(0):=\{x \in E:\|x\| \leq R\}$, for $i=1,2,3$. 
Let $E$ be a smooth and strictly convex Banach space, $C$ a nonempty closed convex subset of $E$, and $A: C \rightarrow E^{*}$ a monotone operator satisfying

$$
D(A) \subseteq C \subseteq J^{-1}\left(\cap_{r>0} R(J+r A)\right),
$$

for $r>0$. Then, we can define the resolvent $Q_{r}: C \rightarrow D(A)$ of $A$ by

$$
Q_{r} x:=\{z \in D(A): J x \in J z+r A z\}, \quad \forall x \in C .
$$

In other words, $Q_{r} x=(J+r A)^{-1} J x$ for $x \in C$. We know that $Q_{r} x$ is single-valued mapping from $C$ into $D(A)$, for all $x \in C$ and $r>0$ and $F\left(Q_{r}\right)=A^{-1}(0)$, where $F\left(Q_{r}\right)$ is the set of fixed points of $Q_{r}$ (see, [4]).

Lemma 2.8 (see [24]). Let $E$ be a smooth and strictly convex Banach space, $C$ a nonempty closed convex subset of $E$, and $A \subset E \times E^{*}$ a monotone operator satisfying (2.8) and $A^{-1}(0)$ is nonempty. Let $Q_{r}$ be the resolvent of $A$. Then, for each $r>0$,

$$
\phi\left(u, Q_{r} x\right)+\phi\left(Q_{r} x, x\right) \leq \phi(u, x)
$$

for all $u \in A^{-1}(0)$ and $x \in C$, that is, $Q_{r}$ is relatively nonexpansive.

Lemma 2.9 (see [25]). Let $\left\{a_{n}\right\}$ be a sequence of nonnegative real numbers satisfying the following relation:

$$
a_{n+1} \leq\left(1-\beta_{n}\right) a_{n}+\beta_{n} \delta_{n}, \quad n \geq n_{0}
$$

where $\left\{\beta_{n}\right\} \subset(0,1)$ and $\left\{\delta_{n}\right\} \subset R$ satisfying the following conditions: $\lim _{n \rightarrow \infty} \beta_{n}=0, \sum_{n=1}^{\infty} \beta_{n}=\infty$, and $\lim \sup _{n \rightarrow \infty} \delta_{n} \leq 0$. Then, $\lim _{n \rightarrow \infty} a_{n}=0$.

Lemma 2.10 (see [26]). Let $\left\{a_{n}\right\}$ be sequences of real numbers such that there exists a subsequence $\left\{n_{i}\right\}$ of $\{n\}$ such that $a_{n_{i}}<a_{n_{i}+1}$ for all $i \in N$. Then, there exists a nondecreasing sequence $\left\{m_{k}\right\} \subset N$ such that $m_{k} \rightarrow \infty$, and the following properties are satisfied by all (sufficiently large) numbers $k \in N$ :

$$
a_{m_{k}} \leq a_{m_{k}+1}, \quad a_{k} \leq a_{m_{k}+1} .
$$

In fact, $m_{k}=\max \left\{j \leq k: a_{j}<a_{j+1}\right\}$.

\section{Main Result}

We note that, as it is mentioned in [27], if $C$ is a subset of a real Banach space $E$ and $A: C \rightarrow$ $E^{*}$ is a mapping satisfying $\|A x\| \leq\|A x-A p\|$, for all $x \in C$ and $p \in \operatorname{VI}(C, A)$, then

$$
\mathrm{VI}(C, A)=A^{-1}(0)=\{p \in C: A p=0\} .
$$


In fact, clearly, $A^{-1}(0) \subseteq \operatorname{VI}(C, A)$. Now, we show that $\operatorname{VI}(C, A) \subseteq A^{-1}(0)$. Let $p \in$ $\mathrm{VI}(C, A)$, then we have by hypothesis that $\|A p\| \leq\|A p-A p\|=0$ which implies that $p \in$ $A^{-1}(0)$. Hence, $\operatorname{VI}(C, A) \subseteq A^{-1}(0)$. Therefore, $\operatorname{VI}(C, A)=A^{-1}(0)$. Now we prove the main theorem of our paper.

Theorem 3.1. Let $C$ be a nonempty, closed, and convex subset of a uniformly convex and uniformly smooth real Banach space $E$. Let $A: C \rightarrow E^{*}$ be a monotone mapping satisfying (2.8) and $\|A x\| \leq$ $\|A x-A p\|$, for all $x \in C$ and $p \in \operatorname{VI}(C, A)$. Let $T: C \rightarrow C$ be a uniformly L-Lipschitzian relatively asymptotically nonexpansive mapping with sequence $\left\{k_{n}\right\}$. Assume that $F:=\operatorname{VI}(C, A) \cap F(S)$ is nonempty. Let $Q_{r}$ be the resolvent of $A$ and $\left\{x_{n}\right\}$ a sequence generated by

$$
\begin{gathered}
x_{0}=w \in C, \text { chosen arbitrarily, } \\
y_{n}=\Pi_{C} J^{-1}\left(\alpha_{n} J w+\left(1-\alpha_{n}\right) J x_{n}\right), \\
x_{n+1}=J^{-1}\left(\beta_{n} J x_{n}+\gamma_{n} J T^{n} y_{n}+\theta_{n} J Q_{r} y_{n}\right),
\end{gathered}
$$

where $\alpha_{n} \in(0,1)$ such that $\lim _{n \rightarrow \infty} \alpha_{n}=0, \lim _{n \rightarrow \infty}\left(\left(k_{n}-1\right) / \alpha_{n}\right)=0, \sum_{n=1}^{\infty} \alpha_{n}=\infty$, $\left\{\beta_{n}\right\},\left\{\gamma_{n}\right\},\left\{\theta_{n}\right\} \subset[c, d] \subset(0,1)$ such that $\beta_{n}+\gamma_{n}+\theta_{n}=1$. Then, $\left\{x_{n}\right\}$ converges strongly to an element of $F$.

Proof. Let $p:=\Pi_{F} w$. Then, from (3.2), Lemma 2.3, and property of $\phi$, we get that

$$
\begin{aligned}
\phi\left(p, y_{n}\right) & =\phi\left(p, \Pi_{C} J^{-1}\left(\alpha_{n} J w+\left(1-\alpha_{n}\right) J x_{n}\right)\right) \\
& \leq \phi\left(p, J^{-1}\left(\alpha_{n} J w+\left(1-\alpha_{n}\right) J x_{n}\right)\right) \\
& =\|p\|^{2}-2\left\langle p, \alpha_{n} J w+\left(1-\alpha_{n}\right) J x_{n}\right\rangle+\left\|\alpha_{n} J w+\left(1-\alpha_{n}\right) J x_{n}\right\|^{2} \\
& \leq\|p\|^{2}-2 \alpha_{n}\langle p, J w\rangle-2\left(1-\alpha_{n}\right)\left\langle p, J x_{n}\right\rangle+\alpha_{n}\|J w\|^{2}+\left(1-\alpha_{n}\right)\left\|J x_{n}\right\|^{2} \\
& =\alpha_{n} \phi(p, w)+\left(1-\alpha_{n}\right) \phi\left(p, x_{n}\right) .
\end{aligned}
$$

Now, from (3.2) and relatively asymptotically nonexpansiveness of $T$, relatively nonexpansiveness of $Q_{r}$, property of $\phi$, and (3.3), we get that

$$
\begin{aligned}
\phi\left(p, x_{n+1}\right) & =\phi\left(p, J^{-1}\left(\beta_{n} J x_{n}+\gamma_{n} J T^{n} y_{n}+\theta_{n} J Q_{r} y_{n}\right)\right) \\
& \leq \beta_{n} \phi\left(p, x_{n}\right)+\gamma_{n} \phi\left(p, T^{n} y_{n}\right)+\theta_{n} \phi\left(p, Q_{r} y_{n}\right) \\
& \leq \beta_{n} \phi\left(p, x_{n}\right)+\gamma_{n} k_{n} \phi\left(p, y_{n}\right)+\theta_{n} \phi\left(p, y_{n}\right) \\
& \leq \beta_{n} \phi\left(p, x_{n}\right)+\left(\gamma_{n} k_{n}+\theta_{n}\right) \phi\left(p, y_{n}\right) \\
& \leq \beta_{n} \phi\left(p, x_{n}\right)+\left(\gamma_{n} k_{n}+\theta_{n}\right)\left[\alpha_{n} \phi(p, w)+\left(1-\alpha_{n}\right) \phi\left(p, x_{n}\right)\right] \\
& \leq\left(\gamma_{n} k_{n}+\theta_{n}\right) \alpha_{n} \phi(p, w)+\left[\beta_{n}+\left(\gamma_{n} k_{n}+\theta_{n}\right)\left(1-\alpha_{n}\right)\right] \phi\left(p, x_{n}\right) \\
& \leq\left(\gamma_{n} k_{n}+\theta_{n}\right) \alpha_{n} \phi(p, w)+\left[\left(1-\alpha_{n}\left(\gamma_{n} k_{n}+\theta_{n}\right)\right)+\gamma_{n}\left(k_{n}-1\right)\right] \times \phi\left(p, x_{n}\right) \\
& \leq c_{n} \phi(p, w)+\left[1-(1-\epsilon) c_{n}\right] \phi\left(p, x_{n}\right),
\end{aligned}
$$


where $c_{n}=\alpha_{n}\left(\gamma_{n} k_{n}+\theta_{n}\right)$, since there exists $N_{0}>0$ such that $\gamma_{n}\left(k_{n}-1\right) / \alpha_{n} \leq \epsilon\left(\gamma_{n} k_{n}+\theta_{n}\right)$ for all $n \geq N_{0}$ and for some $\epsilon>0$ satisfying $(1-\epsilon) c_{n} \leq 1$. Thus, by induction,

$$
\phi\left(p, x_{n+1}\right) \leq \max \left\{\phi\left(p, x_{0}\right),(1-\epsilon)^{-1} \phi(p, w)\right\}, \quad \forall n \geq N_{0}
$$

which implies that $\left\{x_{n}\right\}$, and hence $\left\{y_{n}\right\}$ is bounded. Now, let $z_{n}=J^{-1}\left(\alpha_{n} J w+\left(1-\alpha_{n}\right) J x_{n}\right)$. Then we have that $y_{n}=\Pi_{C} z_{n}$. Using Lemmas $2.3,2.5$, and property of $\phi$, we obtain that

$$
\begin{aligned}
\phi\left(p, y_{n}\right) & \leq \phi\left(p, z_{n}\right)=V\left(p, J z_{n}\right) \\
& \leq V\left(p, J z_{n}-\alpha_{n}(J w-J p)\right)-2\left\langle z_{n}-p,-\alpha_{n}(J w-J p)\right\rangle \\
& =\phi\left(p, J^{-1}\left(\alpha_{n} J p+\left(1-\alpha_{n}\right) J w_{n}\right)\right)+2 \alpha_{n}\left\langle z_{n}-p, J w-J p\right\rangle \\
& \leq \alpha_{n} \phi(p, p)+\left(1-\alpha_{n}\right) \phi\left(p, w_{n}\right)+2 \alpha_{n}\left\langle z_{n}-p, J w-J p\right\rangle \\
& =\left(1-\alpha_{n}\right) \phi\left(p, w_{n}\right)+2 \alpha_{n}\left\langle z_{n}-p, J w-J p\right\rangle \\
& \leq\left(1-\alpha_{n}\right) \phi\left(p, x_{n}\right)+2 \alpha_{n}\left\langle z_{n}-p, J w-J p\right\rangle .
\end{aligned}
$$

Furthermore, from (3.2), Lemma 2.7, relatively asymptotically nonexpansiveness of $T$, relatively nonexpansiveness of $Q_{r}$, and (3.6), we have that

$$
\begin{aligned}
\phi\left(p, x_{n+1}\right)= & \phi\left(p, J^{-1}\left(\beta_{n} J x_{n}+\gamma_{n} J T^{n} y_{n}+\theta_{n} J Q_{r} y_{n}\right)\right) \\
= & \|p\|^{2}-\left\langle p, \beta_{n} J x_{n}+\gamma_{n} J T^{n} y_{n}+\theta_{n} J Q_{r} y_{n}\right\rangle+\left\|\beta_{n} J x_{n}+\gamma_{n} J T^{n} y_{n}+\theta_{n} J Q_{r} y_{n}\right\|^{2} \\
\leq & \|p\|^{2}-2 \beta_{n}\left\langle p, J x_{n}\right\rangle-2 \gamma_{n}\left\langle p, J T^{n} y_{n}\right\rangle-2 \theta_{n}\left\langle p, J Q_{r} y_{n}\right\rangle \\
& +\beta_{n}\left\|J x_{n}\right\|^{2}+\gamma_{n}\left\|J T^{n} y_{n}\right\|^{2}+\theta_{n}\left\|J Q_{r} y_{n}\right\|^{2}-\gamma_{n} \beta_{n} g\left(\left\|J x_{n}-J T^{n} y_{n}\right\|\right) \\
\leq & \beta_{n} \phi\left(p, x_{n}\right)+\gamma_{n} \phi\left(p, T^{n} y_{n}\right)+\theta_{n} \phi\left(p, Q_{r} y_{n}\right)-\gamma_{n} \beta_{n} g\left(\left\|J x_{n}-J T^{n} y_{n}\right\|\right) \\
\leq & \beta_{n} \phi\left(p, x_{n}\right)+\left(\gamma_{n}+\theta_{n}\right) \phi\left(p, y_{n}\right)+\gamma_{n}\left(k_{n}-1\right) \phi\left(p, y_{n}\right)-\gamma_{n} \beta_{n} g\left(\left\|J x_{n}-J T^{n} y_{n}\right\|\right) \\
\leq & \beta_{n} \phi\left(p, x_{n}\right)+\left(\gamma_{n}+\theta_{n}\right)\left[\left(1-\alpha_{n}\right) \phi\left(p, x_{n}\right)+2 \alpha_{n}\left\langle z_{n}-p, J w-J p\right\rangle\right] \\
& +\gamma_{n}\left(k_{n}-1\right) \phi\left(p, y_{n}\right)-\gamma_{n} \beta_{n} g\left(\left\|J x_{n}-J T^{n} y_{n}\right\|\right) \\
\leq & {\left[\beta_{n}+\left(\gamma_{n}+\theta_{n}\right)\left(1-\alpha_{n}\right)\right] \phi\left(p, x_{n}\right)+2 \alpha_{n}\left(\gamma_{n}+\theta_{n}\right)\left\langle z_{n}-p, J w-J p\right\rangle } \\
& +\gamma_{n}\left(k_{n}-1\right) \phi\left(p, y_{n}\right)-\gamma_{n} \beta_{n} g\left(\left\|J x_{n}-J T^{n} y_{n}\right\|\right) \\
\leq & \left(1-\delta_{n}\right) \phi\left(p, x_{n}\right)+2 \delta_{n}\left\langle z_{n}-p, J w-J p\right\rangle+\left(k_{n}-1\right) M-\gamma_{n} \beta_{n} g\left(\left\|J x_{n}-J T^{n} y_{n}\right\|\right) \\
&
\end{aligned}
$$

for some $M>0$, where $\delta_{n}=\left(\gamma_{n}+\theta_{n}\right) \alpha_{n}$. 
Similarly, from (3.7), we obtain that

$$
\begin{aligned}
\phi\left(p, x_{n+1}\right) & =\phi\left(p, J^{-1}\left(\beta_{n} J x_{n}+\gamma_{n} J T^{n} y_{n}+\theta_{n} J Q_{r} y_{n}\right)\right) \\
& \leq\left(1-\delta_{n}\right) \phi\left(p, x_{n}\right)+2 \delta\left\langle z_{n}-p, J w-J p\right\rangle+\left(k_{n}-1\right) M-\theta_{n} \beta_{n} g\left(\left\|J x_{n}-J Q_{r} y_{n}\right\|\right) \\
& \leq\left(1-\delta_{n}\right) \phi\left(p, x_{n}\right)+2 \delta_{n}\left\langle z_{n}-p, J w-J p\right\rangle+\left(k_{n}-1\right) M,
\end{aligned}
$$

for some $M>0$. Note that $\left\{\delta_{n}\right\}$ satisfies that $\lim _{n \rightarrow \infty} \delta_{n}=0$ and $\sum \delta_{n}=\infty$.

Now, the rest of the proof is divided into two parts.

Case 1. Suppose that there exists $n_{0} \in N>N_{0}$ such that $\left\{\phi\left(p, x_{n}\right)\right\}$ is nonincreasing for all $n \geq n_{0}$. In this situation, $\left\{\phi\left(p, x_{n}\right)\right\}$ is then convergent. Then, from (3.8) and (*), we have that

$$
\gamma_{n} \beta_{n} g\left(\left\|J x_{n}-J T^{n} y_{n}\right\|\right) \longrightarrow 0, \quad \theta_{n} \beta_{n} g\left(\left\|J x_{n}-J Q_{r} y_{n}\right\|\right) \longrightarrow 0,
$$

which implies, by the property of $g$, that

$$
J x_{n}-J T^{n} y_{n} \longrightarrow 0, \quad J x_{n}-J Q_{r} y_{n} \longrightarrow 0, \quad \text { as } n \longrightarrow \infty,
$$

and, hence, since $J^{-1}$ is uniformly continuous on bounded sets, we obtain that

$$
x_{n}-T^{n} y_{n} \longrightarrow 0, \quad x_{n}-Q_{r} y_{n} \longrightarrow 0, \quad \text { as } n \longrightarrow \infty
$$

Furthermore, Lemma 2.3, property of $\phi$, and the fact that $\alpha_{n} \rightarrow 0$ as $n \rightarrow \infty$ imply that

$$
\begin{aligned}
\phi\left(x_{n}, y_{n}\right) & =\phi\left(x_{n}, \Pi_{C} z_{n}\right) \leq \phi\left(x_{n}, z_{n}\right) \\
& =\phi\left(x_{n}, J^{-1}\left(\alpha_{n} J w+\left(1-\alpha_{n}\right) J x_{n}\right)\right. \\
& \leq \alpha_{n} \phi\left(x_{n}, w\right)+\left(1-\alpha_{n}\right) \phi\left(x_{n}, x_{n}\right) \\
& \leq \alpha_{n} \phi\left(x_{n}, w\right)+\left(1-\alpha_{n}\right) \phi\left(x_{n}, x_{n}\right) \longrightarrow 0, \quad \text { as } n \longrightarrow \infty,
\end{aligned}
$$

and hence

$$
x_{n}-y_{n} \longrightarrow 0, \quad x_{n}-z_{n} \longrightarrow 0, \quad \text { as } n \longrightarrow \infty
$$

Therefore, from (3.12) and (3.14), we obtain that

$$
y_{n}-z_{n} \longrightarrow 0, \quad y_{n}-T^{n} y_{n} \longrightarrow 0, \quad y_{n}-Q_{r} y_{n} \longrightarrow 0, \quad \text { as } n \longrightarrow \infty
$$

But observe that from (3.2) and (3.11), we have

$$
\left\|J x_{n+1}-J x_{n}\right\| \leq \gamma_{n}\left\|J T^{n} y_{n}-J x_{n}\right\|+\theta_{n}\left\|J Q_{r} y_{n}-J x_{n}\right\| \longrightarrow 0
$$


as $n \rightarrow \infty$. Thus, as $J^{-1}$ is uniformly continuous on bounded sets, we have that $x_{n+1}-x_{n} \rightarrow 0$ which implies from (3.14) that $x_{n+1}-y_{n} \rightarrow 0$, as $n \rightarrow \infty$, and that

$$
\left\|y_{n+1}-y_{n}\right\| \leq\left\|y_{n+1}-x_{n+1}\right\|+\left\|x_{n+1}-y_{n}\right\| \longrightarrow 0, \quad \text { as } n \longrightarrow \infty
$$

Furthermore, since

$$
\begin{aligned}
\left\|y_{n}-T y_{n}\right\| \leq & \left\|y_{n}-T^{n} y_{n}\right\|+\left\|T^{n} y_{n}-T^{n+1} y_{n}\right\|+\left\|T^{n+1} y_{n}-T y_{n}\right\|, \\
\leq & \left\|y_{n}-T^{n} y_{n}\right\|+\left\|T^{n+1} y_{n}-T^{n+1} y_{n+1}\right\|+\left\|T^{n+1} y_{n+1}-y_{n+1}\right\| \\
& \quad+\left\|y_{n+1}-y_{n}\right\|+\left\|y_{n}-T^{n} y_{n}\right\|+\left\|T\left(T^{n} y_{n}\right)-T y_{n}\right\| \\
\leq & \left\|y_{n}-T^{n} y_{n}\right\|+L\left\|y_{n}-y_{n+1}\right\|+\left\|T^{n+1} y_{n+1}-y_{n+1}\right\| \\
& \quad+\left\|y_{n+1}-y_{n}\right\|+\left\|y_{n}-T^{n} y_{n}\right\|+\left\|T\left(T^{n} y_{n}\right)-T y_{n}\right\| \\
\leq & 2\left\|y_{n}-T^{n} y_{n}\right\|+(1+L)\left\|y_{n}-y_{n+1}\right\|+\left\|T^{n+1} y_{n+1}-y_{n+1}\right\|+\left\|T\left(T^{n} y_{n}\right)-T y_{n}\right\|,
\end{aligned}
$$

we have from (3.17), (3.15), and uniform continuity of $T$ that

$$
\left\|y_{n}-T y_{n}\right\| \longrightarrow 0, \quad \text { as } n \longrightarrow \infty
$$

Since $\left\{z_{n}\right\}$ is bounded and $E$ is reflexive, we choose a subsequence $\left\{z_{n_{i}}\right\}$ of $\left\{z_{n}\right\}$ such that $z_{n_{i}} \rightarrow z$ and $\lim \sup _{n \rightarrow \infty}\left\langle z_{n}-p, J w-J p\right\rangle=\lim _{i \rightarrow \infty}\left\langle z_{n_{i}}-p, J w-J p\right\rangle$. Then, from (3.14) and (3.15) we get that

$$
y_{n_{i}} \rightarrow z, x_{n_{i}} \rightarrow z, \quad \text { as } i \longrightarrow \infty
$$

Thus, since $T$ satisfies condition (N3), we obtain from (3.19) that $z \in F(T)$ and the fact that $Q_{r}$ is relatively nonexpansive and $y_{n_{i}}-z$ implies that $z \in F\left(Q_{r}\right)=A^{-1}(0)$, and, hence, using (3.1), we obtain that $z \in \operatorname{VI}(C, A)$.

Therefore, from the above discussions, we obtain that $z \in F:=F(T) \cap \operatorname{VI}(C, A)$. Hence, by Lemma 2.6, we immediately obtain that $\lim \sup _{n \rightarrow \infty}\left\langle z_{n}-p, J w-J p\right\rangle=\lim _{i \rightarrow \infty}\left\langle z_{n_{i}}-p, J w-\right.$ $J p\rangle=\langle z-p, J w-J p\rangle \leq 0$. It follows from Lemma 2.9 and (3.9) that $\phi\left(p, x_{n}\right) \rightarrow 0$, as $n \rightarrow \infty$. Consequently, $x_{n} \rightarrow p$.

Case 2. Suppose that there exists a subsequence $\left\{n_{i}\right\}$ of $\{n\}$ such that

$$
\phi\left(p, x_{n_{i}}\right)<\phi\left(p, x_{n_{i}+1}\right)
$$

for all $i \in N$. Then, by Lemma 2.10, there exists a nondecreasing sequence $\left\{m_{k}\right\} \subset N$ such that $m_{k} \rightarrow \infty, \phi\left(p, x_{m_{k}}\right) \leq \phi\left(p, x_{m_{k}+1}\right)$ and $\phi\left(p, x_{k}\right) \leq \phi\left(p, x_{m_{k}+1}\right)$ for all $k \in N$. Then, from (3.8), (*) and the fact $\delta_{n} \rightarrow 0$, we have

$$
g\left(\left\|J x_{m_{k}}-J T^{m_{k}} y_{m_{k}}\right\|\right) \longrightarrow 0, \quad g\left(\left\|J x_{m_{k}}-J Q_{r} y_{m_{k}}\right\|\right) \longrightarrow 0, \quad \text { as } k \longrightarrow \infty
$$


Thus, using the same proof as in Case 1 , we obtain that $y_{m_{k}}-T y_{m_{k}} \rightarrow 0, y_{m_{k}}-Q_{r} y_{m_{k}} \rightarrow 0$, as $k \rightarrow \infty$, and, hence, we obtain that

$$
\limsup _{k \rightarrow \infty}\left\langle z_{m_{k}}-p, J w-J p\right\rangle \leq 0
$$

Then, from (3.9), we have that

$$
\phi\left(p, x_{m_{k}+1}\right) \leq\left(1-\delta_{m_{k}}\right) \phi\left(p, x_{m_{k}}\right)+2 \delta_{m_{k}}\left\langle z_{m_{k}}-p, J w-J p\right\rangle+\left(k_{m_{k}}-1\right) M .
$$

Since $\phi\left(p, x_{m_{k}}\right) \leq \phi\left(p, x_{m_{k}+1}\right),(3.24)$ implies that

$$
\begin{aligned}
\delta_{m_{k}} \phi\left(p, x_{m_{k}}\right) & \leq \phi\left(p, x_{m_{k}}\right)-\phi\left(p, x_{m_{k}+1}\right)+2 \delta_{m_{k}}\left\langle z_{m_{k}}-p, J w-J p\right\rangle+\left(k_{m_{k}}-1\right) M \\
& \leq 2 \delta_{m_{k}}\left\langle z_{m_{k}}-p, J w-J p\right\rangle+\left(k_{m_{k}}-1\right) M .
\end{aligned}
$$

In particular, since $\delta_{m_{k}}>0$, we get

$$
\phi\left(p, x_{m_{k}}\right) \leq 2\left\langle z_{m_{k}}-p, J w-J p\right\rangle+\frac{\left(k_{m_{k}}-1\right)}{\delta_{m_{k}}} M
$$

Then, from (3.23) and the fact that $\left(k_{m_{k}}-1\right) / \delta_{m_{k}} \rightarrow 0$, we obtain $\phi\left(p, x_{m_{k}}\right) \rightarrow 0$, as $k \rightarrow \infty$. This together with (3.24) gives $\phi\left(p, x_{m_{k}+1}\right) \rightarrow 0$, as $k \rightarrow \infty$. But $\phi\left(p, x_{k}\right) \leq \phi\left(p, x_{m_{k}+1}\right)$, for all $k \in N$, thus we obtain that $x_{k} \rightarrow p$. Therefore, from the above two cases, we can conclude that $\left\{x_{n}\right\}$ converges strongly to $p$ and the proof is complete. corollary.

If, in Theorem 3.1, we assume that $T$ is relatively nonexpansive, we get the following

Corollary 3.2. Let $C$ be a nonempty, closed, and convex subset of a uniformly convex and uniformly smooth real Banach space $E$. Let $A: C \rightarrow E^{*}$ be a monotone mapping satisfying (2.8) and $\|A x\| \leq$ $\|A x-A p\|$, for all $x \in C$ and $p \in \operatorname{VI}(C, A)$. Let $T: C \rightarrow C$ be a relatively nonexpansive mapping. Assume that $F:=\operatorname{VI}(C, A) \cap F(S)$ is nonempty. Let $\left\{x_{n}\right\}$ be a sequence generated by

$$
\begin{gathered}
x_{0}=w \in C, \text { chosen arbitrarily, } \\
y_{n}=\Pi_{C} J^{-1}\left(\alpha_{n} J w+\left(1-\alpha_{n}\right) J x_{n}\right), \\
x_{n+1}=J^{-1}\left(\beta_{n} J x_{n}+\gamma_{n} J T y_{n}+\theta_{n} J Q_{r} y_{n}\right),
\end{gathered}
$$

where $\alpha_{n} \in(0,1)$ such that $\lim _{n \rightarrow \infty} \alpha_{n}=0, \sum_{n=1}^{\infty} \alpha_{n}=\infty,\left\{\beta_{n}\right\},\left\{\gamma_{n}\right\},\left\{\theta_{n}\right\} \subset[c, d] \subset(0,1)$ such that $\beta_{n}+\gamma_{n}+\theta_{n}=1$. Then, $\left\{x_{n}\right\}$ converges strongly to an element of $F$.

Proof. We note that the method of proof of Theorem 3.1 provides the required assertion.

If $E=H$, a real Hilbert space, then $E$ is uniformly convex and uniformly smooth real Banach space. In this case, $J=I$, identity map on $H$ and $\Pi_{C}=P_{C}$, projection mapping from $H$ onto $C$. Thus, the following corollary holds. 
Corollary 3.3. Let $C$ be a nonempty, closed, and convex subset of a real Hilbert space $H$. Let $A: C \rightarrow$ $H$ be a monotone mapping satisfying (2.8) and $\|A x\| \leq\|A x-A p\|$, for all $x \in C$ and $p \in V I(C, A)$. Let $T: C \rightarrow C$ be a uniformly L-Lipschitzian relatively asymptotically nonexpansive mapping with sequence $\left\{k_{n}\right\}$. Assume that $F:=V I(C, A) \cap F(S)$ is nonempty. Let $\left\{x_{n}\right\}$ be a sequence generated by

$$
\begin{gathered}
x_{0}=w \in C, \text { chosen arbitrarily, } \\
y_{n}=P_{C}\left(\alpha_{n} w+\left(1-\alpha_{n}\right) x_{n}\right), \\
x_{n+1}=\beta_{n} x_{n}+\gamma_{n} T^{n} y_{n}+\theta_{n} Q_{r} y_{n}
\end{gathered}
$$

where $\alpha_{n} \in(0,1)$ such that $\lim _{n \rightarrow \infty} \alpha_{n}=0, \lim _{n \rightarrow \infty}\left(\left(k_{n}-1\right) / \alpha_{n}\right)=0, \sum_{n=1}^{\infty} \alpha_{n}=\infty$, $\left\{\beta_{n}\right\},\left\{\gamma_{n}\right\},\left\{\theta_{n}\right\} \subset[c, d] \subset(0,1)$ such that $\beta_{n}+\gamma_{n}+\theta_{n}=1$. Then, $\left\{x_{n}\right\}$ converges strongly to an element of $F$.

Now, we state the second main theorem of our paper.

Theorem 3.4. Let $C$ be a nonempty, closed, and convex subset of a uniformly convex and uniformly smooth real Banach space $E$. Let $A: C \rightarrow E^{*}$ be a monotone mapping satisfying (2.8). Let $T: C \rightarrow C$ be a uniformly L-Lipschitzian relatively asymptotically nonexpansive mapping with sequence $\left\{k_{n}\right\}$. Assume that $F:=A^{-1}(0) \cap F(S)$ is nonempty. Let $Q_{r}$ be the resolvent of $A$ and $\left\{x_{n}\right\}$ a sequence generated by

$$
\begin{gathered}
x_{0}=w \in C, \text { chosen arbitrarily, } \\
y_{n}=\Pi_{C} J^{-1}\left(\alpha_{n} J w+\left(1-\alpha_{n}\right) J x_{n}\right), \\
x_{n+1}=J^{-1}\left(\beta_{n} J x_{n}+\gamma_{n} J T^{n} y_{n}+\theta_{n} J Q_{r} y_{n}\right),
\end{gathered}
$$

where $\alpha_{n} \in(0,1)$ such that $\lim _{n \rightarrow \infty} \alpha_{n}=0, \lim _{n \rightarrow \infty}\left(\left(k_{n}-1\right) / \alpha_{n}\right)=0, \sum_{n=1}^{\infty} \alpha_{n}=\infty$, $\left\{\beta_{n}\right\},\left\{\gamma_{n}\right\},\left\{\theta_{n}\right\} \subset[c, d] \subset(0,1)$ such that $\beta_{n}+\gamma_{n}+\theta_{n}=1$. Then, $\left\{x_{n}\right\}$ converges strongly to an element of $F$.

Proof. Similar method of proof of Theorem 3.1 provides the required assertion.

If, in Theorem 3.4, $A=0$, then we have the following corollary. Similar proof of Theorem 3.1 provides the assertion.

Corollary 3.5. Let $C$ be a nonempty, closed, and convex subset of a uniformly convex and uniformly smooth real Banach space $E$. Let $T: C \rightarrow C$ be a uniformly L-Lipschitzian relatively asymptotically nonexpansive mapping with sequence $\left\{k_{n}\right\}$. Assume that $F:=F(S)$ is nonempty. Let $\left\{x_{n}\right\}$ be a sequence generated by

$$
\begin{gathered}
x_{0}=w \in C, \text { chosen arbitrarily, } \\
y_{n}=\Pi_{C} J^{-1}\left(\alpha_{n} J w+\left(1-\alpha_{n}\right) J x_{n}\right), \\
x_{n+1}=J^{-1}\left(\beta_{n} J x_{n}+\left(1-\beta_{n}\right) J T^{n} y_{n}\right),
\end{gathered}
$$

where $\alpha_{n} \in(0,1)$ such that $\lim _{n \rightarrow \infty} \alpha_{n}=0, \lim _{n \rightarrow \infty}\left(\left(k_{n}-1\right) / \alpha_{n}\right)=0, \sum_{n=1}^{\infty} \alpha_{n}=\infty,\left\{\beta_{n}\right\} \subset$ $[c, d] \subset(0,1)$. Then, $\left\{x_{n}\right\}$ converges strongly to an element of $F$. 
If, in Theorem 3.4, $T=I$, identity mapping on $C$, then we have the following corollary.

Corollary 3.6. Let $C$ be a nonempty, closed, and convex subset of a uniformly smooth and uniformly convex real Banach space E. Let $A: C \rightarrow E^{*}$ be a monotone mapping satisfying (2.8). Assume that $F:=A^{-1}(0)$ is nonempty. Let $Q_{r}$ be the resolvent of $A$ and $\left\{x_{n}\right\}$ a sequence generated by

$$
\begin{gathered}
x_{0}=w \in C, \text { chosen arbitrarily, } \\
y_{n}=\Pi_{C} J^{-1}\left(\alpha_{n} J w+\left(1-\alpha_{n}\right) J x_{n}\right), \\
x_{n+1}=J^{-1}\left(\beta_{n} J x_{n}+\left(1-\beta_{n}\right) J Q_{r} y_{n}\right),
\end{gathered}
$$

where $\alpha_{n} \in(0,1)$ such that $\lim _{n \rightarrow \infty} \alpha_{n}=0, \sum_{n=1}^{\infty} \alpha_{n}=\infty,\left\{\beta_{n}\right\} \subset[c, d] \subset(0,1)$. Then, $\left\{x_{n}\right\}$ converges strongly to an element of $F$. corollary.

If, in Theorem 3.4, we assume that $T$ is relatively nonexpansive, we get the following

Corollary 3.7. Let $C$ be a nonempty, closed, and convex subset of a uniformly convex and uniformly smooth real Banach space $E$. Let $A: C \rightarrow E^{*}$ be a monotone mapping satisfying (2.8). Let $T: C \rightarrow C$ be a relatively nonexpansive mapping. Assume that $F:=A^{-1}(0) \cap F(S)$ is nonempty. Let $\left\{x_{n}\right\}$ be a sequence generated by

$$
\begin{gathered}
x_{0}=w \in C, \text { chosen arbitrarily, } \\
y_{n}=\Pi_{C} J^{-1}\left(\alpha_{n} J w+\left(1-\alpha_{n}\right) J x_{n}\right), \\
x_{n+1}=J^{-1}\left(\beta_{n} J x_{n}+\gamma_{n} J T y_{n}+\theta_{n} J Q_{r} y_{n}\right),
\end{gathered}
$$

where $\alpha_{n} \in(0,1)$ such that $\lim _{n \rightarrow \infty} \alpha_{n}=0, \sum_{n=1}^{\infty} \alpha_{n}=\infty,\left\{\beta_{n}\right\},\left\{\gamma_{n}\right\},\left\{\theta_{n}\right\} \subset[c, d] \subset(0,1)$ such that $\beta_{n}+\gamma_{n}+\theta_{n}=1$. Then, $\left\{x_{n}\right\}$ converges strongly to an element of $F$.

We may also get the following corollary for a common zero of monotone mappings.

Corollary 3.8. Let $C$ be a nonempty, closed, and convex subset of a uniformly convex and uniformly smooth real Banach space $E$. Let $A, B: C \rightarrow E^{*}$ be monotone mappings satisfying (2.8). Suppose that $T_{1}=(J+r A)^{-1} J$ and $T_{2}=(J+r B)^{-1} J$. Assume that $F:=A^{-1}(0) \cap B^{-1}(0)$ is nonempty. Let $\left\{x_{n}\right\}$ be a sequence generated by

$$
\begin{gathered}
x_{0}=w \in C, \text { chosen arbitrarily, } \\
y_{n}=\Pi_{C} J^{-1}\left(\alpha_{n} J w+\left(1-\alpha_{n}\right) J x_{n}\right), \\
x_{n+1}=J^{-1}\left(\beta_{n} J x_{n}+\gamma_{n} J T_{1} y_{n}+\theta_{n} J T_{2} y_{n}\right),
\end{gathered}
$$

where $\alpha_{n} \in(0,1)$ such that $\lim _{n \rightarrow \infty} \alpha_{n}=0, \sum_{n=1}^{\infty} \alpha_{n}=\infty,\left\{\beta_{n}\right\},\left\{\gamma_{n}\right\},\left\{\theta_{n}\right\} \subset[c, d] \subset(0,1)$ such that $\beta_{n}+\gamma_{n}+\theta_{n}=1$. Then, $\left\{x_{n}\right\}$ converges strongly to an element of $F$.

Proof. Clearly, from Lemma 2.8, we know that $T_{1}$ and $T_{2}$ are relatively nonexpansive mappings. We also have that $F\left(T_{1}\right)=A^{-1}(0)$ and $F\left(T_{2}\right)=B^{-1}(0)$. Thus, the conclusion follows from Corollary 3.7. 
Remark 3.9. We remark that from Corollary 3.8 the scheme converges strongly to a common zero of two monotone operators. We may also have the following theorem for a common zero of finite family of monotone mappings.

Theorem 3.10. Let $C$ be a nonempty, closed, and convex subset of a uniformly convex and uniformly smooth real Banach space $E$. Let $A_{i}: C \rightarrow E^{*}, i=1,2, \ldots, N$ be monotone mappings satisfying (2.8). Suppose that $T_{i}=\left(J+r A_{i}\right)^{-1} J$, and assume that $F:=\cap_{i=1}^{N} A_{i}^{-1}(0)$ is nonempty. Let $\left\{x_{n}\right\}$ be a sequence generated by

$$
\begin{gathered}
x_{0}=w \in C, \text { chosen arbitrarily, } \\
y_{n}=\Pi_{C} J^{-1}\left(\alpha_{n} J w+\left(1-\alpha_{n}\right) J x_{n}\right), \\
x_{n+1}=J^{-1}\left(\beta_{n, 0} J x_{n}+\beta_{n, 1} J T_{1} y_{n}+\cdots+\beta_{n, N} J T_{N} y_{n}\right),
\end{gathered}
$$

where $\alpha_{n} \in(0,1)$ such that $\lim _{n \rightarrow \infty} \alpha_{n}=0, \sum_{n=1}^{\infty} \alpha_{n}=\infty,\left\{\beta_{n, i}\right\} \subset[c, d] \subset(0,1)$, for $i=0,1,2, \ldots, N$, such that $\sum_{i=0}^{N} \beta_{n, i}=1$. Then, $\left\{x_{n}\right\}$ converges strongly to an element of $F$.

A monotone mapping $A: C \rightarrow E^{*}$ is said to be maximal monotone if its graph is not properly contained in the graph of any monotone operator. We know that if $A$ is maximal monotone operator, then $A^{-1}(0)$ is closed and convex: see [4] for more details. The following Lemma is well known.

Lemma 3.11 (see [28]). Let $E$ be a smooth and strictly convex and reflexive Banach space, let $C$ be a nonempty closed convex subset of $E$, and let $A: C \rightarrow E^{*}$ be a monotone operator. Then $A$ is maximal if and only if $R(J+r A)=E^{*}$ for all $r>0$.

We note from the above lemma that if $A$ is maximal then it satisfies condition (2.8) and hence we have the following corollary.

Corollary 3.12. Let $C$ be a nonempty, closed, and convex subset of a uniformly convex and uniformly smooth real Banach space $E$. Let $A: C \rightarrow E^{*}$ be a maximal monotone mapping. Let $T: C \rightarrow C$ be a uniformly L-Lipschitzian relatively asymptotically nonexpansive mapping with sequence $\left\{k_{n}\right\}$. Assume that $F:=A^{-1}(0) \cap F(S)$ is nonempty. Let $\left\{x_{n}\right\}$ be a sequence generated by

$$
\begin{gathered}
x_{0}=w \in C, \text { chosen arbitrarily, } \\
y_{n}=\Pi_{C} J^{-1}\left(\alpha_{n} J w+\left(1-\alpha_{n}\right) J x_{n}\right), \\
x_{n+1}=J^{-1}\left(\beta_{n} J x_{n}+\gamma_{n} J T^{n} y_{n}+\theta_{n} J Q_{r} y_{n}\right),
\end{gathered}
$$

where $\alpha_{n} \in(0,1)$ such that $\lim _{n \rightarrow \infty} \alpha_{n}=0, \lim _{n \rightarrow \infty}\left(\left(k_{n}-1\right) / \alpha_{n}\right)=0, \sum_{n=1}^{\infty} \alpha_{n}=\infty$, $\left\{\beta_{n}\right\},\left\{\gamma_{n}\right\},\left\{\theta_{n}\right\} \subset[c, d] \subset(0,1)$ such that $\beta_{n}+\gamma_{n}+\theta_{n}=1$. Then, $\left\{x_{n}\right\}$ converges strongly to an element of $F$.

\section{Application}

In this section, we study the problem of finding a minimizer of a lower semicontinuous continuously convex functional in Banach spaces. 
Theorem 4.1. Let E be a uniformly convex and uniformly smooth real Banach space. Let $f, g: E \rightarrow$ $(-\infty, \infty)$ be a proper lower semicontinuous convex functions. Assume that $F:=(\partial f)^{-1}(0) \cap(\partial g)^{-1}(0)$ is nonempty. Let $\left\{x_{n}\right\}$ be a sequence generated by

$$
\begin{gathered}
x_{0}=w \in C, \text { chosen arbitrarily, } \\
y_{n}=\Pi_{C} J^{-1}\left(\alpha_{n} J w+\left(1-\alpha_{n}\right) J x_{n}\right), \\
h_{n}=\operatorname{argmin}\left\{f(z)+\frac{1}{2 r} \phi\left(z, y_{n}\right), z \in E\right\}, \\
t_{n}=\operatorname{argmin}\left\{g(z)+\frac{1}{2 r} \phi\left(z, y_{n}\right), z \in E\right\}, \\
x_{n+1}=J^{-1}\left(\beta_{n} J x_{n}+\gamma_{n} J h_{n}+\theta_{n} J t_{n}\right),
\end{gathered}
$$

where $\alpha_{n} \in(0,1)$ such that $\lim _{n \rightarrow \infty} \alpha_{n}=0, \sum_{n=1}^{\infty} \alpha_{n}=\infty,\left\{\beta_{n}\right\},\left\{\gamma_{n}\right\},\left\{\theta_{n}\right\} \subset[c, d] \subset(0,1)$ such that $\beta_{n}+\gamma_{n}+\theta_{n}=1$. Then, $\left\{x_{n}\right\}$ converges strongly to an element of $F$.

Proof. Let $A$ and $B$ be operators defined by $A=\partial f$ and $B=\partial g$ and $Q_{r}=(J+r A)^{-1} J, Q_{r}^{B}=$ $(J+r B)^{-1} J$ for all $r>0$. Then, by Rockafellar [29], $A$ and $B$ are maximal monotone mappings. We also have that

$$
\begin{aligned}
& h_{n}=Q_{r}^{A} y=\operatorname{argmin}\left\{f(z)+\frac{1}{2 r} \phi(z, y), z \in E\right\}, \\
& t_{n}=Q_{r}^{B} y=\operatorname{argmin}\left\{g(z)+\frac{1}{2 r} \phi(z, y), z \in E\right\},
\end{aligned}
$$

for all $y \in E$ and $r>0$. Furthermore, we have that $F\left(Q_{r}^{A}\right)=A^{-1}(0)$ and $F\left(Q_{r}^{B}\right)=B^{-1}(0)$. Thus, by Corollary 3.8, we obtain the desired result.

Remark 4.2. Consider the following.

(1) Theorem 3.1 improves and extends the corresponding results of Zegeye et al. [12] and Zegeye and Shahzad [22] in the sense that either our scheme does not require computation of $C_{n+1}$ for each $n \geq 1$ or the space considered is more general.

(2) Corollary 3.5 improves the corresponding results of Nakajo and Takahashi [30] and Matsushita and Takahashi [17] in the sense that either our scheme does not require computation of $C_{n+1}$ for each $n \geq 1$ or the class of mappings considered in our corollary is more general.

(3) Corollary 3.6 improves the corresponding results of Iiduka and Takahashi [11], Iiduka et al. [14], and Alber [1] in the sense that our scheme does not require computation of $C_{n+1}$ for each $n \geq 1$ or the class of mappings considered in our corollary is more general.

\section{References}

[1] Y. I. Alber, "Metric and generalized projection operators in Banach spaces: properties and applications," in Theory and Applications of Nonlinear Operators of Accretive and Monotone Type, vol. 178 of Lecture Notes in Pure and Applied Mathematics, pp. 15-50, Dekker, New York, NY, USA, 1996. 
[2] S. Kamimura and W. Takahashi, "Strong convergence of a proximal-type algorithm in a Banach space," SIAM Journal on Optimization, vol. 13, no. 3, pp. 938-945, 2002.

[3] S. Reich, "A weak convergence theorem for the alternating method with Bergman distance," in Theory and Applications of Nonlinear Operators of Accretive and Monotone Type, A. G. Kartsatos, Ed., vol. 178 of Lecture Notes in Pure and Applied Mathematics, pp. 313-318, Dekker, New York, NY, USA, 1996.

[4] W. Takahashi, Nonlinear Functional Analysis, Kindikagaku, Tokyo, Japan, 1988.

[5] E. H. Zarantonello, "Solving functional equations by contractive averaging," Mathematics Research Center Report 160, Mathematics Research Centre, Univesity of Wisconsin, Madison, Wis, USA, 1960.

[6] G. J. Minty, "Monotone (nonlinear) operators in Hilbert space," Duke Mathematical Journal, vol. 29, pp. 341-346, 1962.

[7] R. I. Kacurovskii, "Monotone operators and convex functionals," Uspekhi Matematicheskikh Nauk, vol. 15, pp. 213-215, 1960.

[8] M. M. Vaŭnberg and R. I. Kačurovskiř, "On the variational theory of non-linear operators and equations," Doklady Akademii Nauk SSSR, vol. 129, pp. 1199-1202, 1959.

[9] D. Kinderlehrer and G. Stampaccia, An Iteration to Variational Inequalities and Their Applications, Academic Press, New York, NY, USA, 1990.

[10] J.-L. Lions and G. Stampacchia, "Variational inequalities," Communications on Pure and Applied Mathematics, vol. 20, pp. 493-519, 1967.

[11] H. Iiduka and W. Takahashi, "Strong convergence studied by a hybrid type method for monotone operators in a Banach space," Nonlinear Analysis. Theory, Methods E Applications, vol. 68, no. 12, pp. 3679-3688, 2008.

[12] H. Zegeye, E. U. Ofoedu, and N. Shahzad, "Convergence theorems for equilibrium problem, variational inequality problem and countably infinite relatively quasi-nonexpansive mappings," Applied Mathematics and Computation, vol. 216, no. 12, pp. 3439-3449, 2010.

[13] H. Zegeye and N. Shahzad, "Strong convergence theorems for monotone mappings and relatively weak nonexpansive mappings," Nonlinear Analysis. Theory, Methods E Applications, vol. 70, no. 7, pp. 2707-2716, 2009.

[14] H. Iiduka, W. Takahashi, and M. Toyoda, "Approximation of solutions of variational inequalities for monotone mappings," Panamerican Mathematical Journal, vol. 14, no. 2, pp. 49-61, 2004.

[15] H. Iiduka and W. Takahashi, "Weak convergence of projection algorithm for variational inequalities in Banach spaces," Journal of Mathematical Analysis and Applications, vol. 339, no. 1, pp. 668-679, 2008.

[16] T.-H. Kim and W. Takahashi, "Strong convergence of modified iteration processes for relatively asymptotically nonexpansive mappings," Taiwanese Journal of Mathematics, vol. 14, no. 6, pp. 21632180, 2010.

[17] S.-Y. Matsushita and W. Takahashi, "A strong convergence theorem for relatively nonexpansive mappings in a Banach space," Journal of Approximation Theory, vol. 134, no. 2, pp. 257-266, 2005.

[18] A. Tada and W. Takahashi, "Weak and strong convergence theorems for a nonexpansive mapping and an equilibrium problem," Journal of Optimization Theory and Applications, vol. 133, no. 3, pp. 359-370, 2007.

[19] W. Takahashi and K. Zembayashi, "Strong and weak convergence theorems for equilibrium problems and relatively nonexpansive mappings in Banach spaces," Nonlinear Analysis. Theory, Methods $\mathcal{E}$ Applications, vol. 70, no. 1, pp. 45-57, 2009.

[20] H. Zegeye and N. Shahzad, "Strong convergence theorems for variational inequality problems and quasi- $\phi$-asymptotically nonexpansive mappings," Journal of Global Optimization. In press.

[21] H. Iiduka and W. Takahashi, "Strong convergence theorems for nonexpansive mappings and $\alpha$ inverse-strongly monotone mappings," Nonlinear Analysis. Theory, Methods E Applications, vol. 61, no. 3, pp. 341-350, 2005.

[22] H. Zegeye and N. Shahzad, "A hybrid approximation method for equilibrium, variational inequality and fixed point problems," Nonlinear Analysis. Hybrid Systems, vol. 4, no. 4, pp. 619-630, 2010.

[23] H. Zegeye and N. Shahzad, "A hybrid scheme for finite families of equilibrium, variational inequality and fixed point problems," Nonlinear Analysis. Theory, Methods E Applications, vol. 74, no. 1, pp. 263272, 2011.

[24] S. Kamimura, F. Kohsaka, and W. Takahashi, "Weak and strong convergence theorems for maximal monotone operators in a Banach space," Set-Valued Analysis, vol. 12, no. 4, pp. 417-429, 2004.

[25] H.-K. Xu, "Another control condition in an iterative method for nonexpansive mappings," Bulletin of the Australian Mathematical Society, vol. 65, no. 1, pp. 109-113, 2002.

[26] P.-E. Maingé, "Strong convergence of projected subgradient methods for nonsmooth and nonstrictly convex minimization," Set-Valued Analysis, vol. 16, no. 7-8, pp. 899-912, 2008. 
[27] H. Zegeye and N. Shahzad, "Approximating common solution of variational inequality problems for two monotone mappings in Banach spaces," Optimization Letters, vol. 5, no. 4, pp. 691-704, 2011.

[28] R. T. Rockafellar, "Monotone operators and proximal point algorithm," Transactions of the American Mathematical Society, vol. 194, pp. 75-88, 1970.

[29] R. T. Rockafellar, "Characterization of the subdifferentials of convex functions," Pacific Journal of Mathematics, vol. 17, pp. 497-510, 1966.

[30] K. Nakajo and W. Takahashi, "Strong convergence theorems for nonexpansive mappings and nonexpansive semigroups," Journal of Mathematical Analysis and Applications, vol. 279, no. 2, pp. 372379, 2003. 


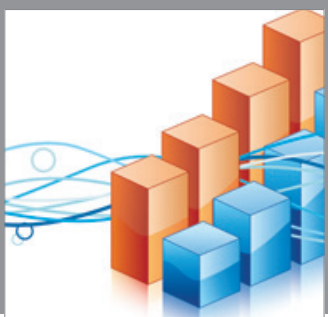

Advances in

Operations Research

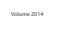

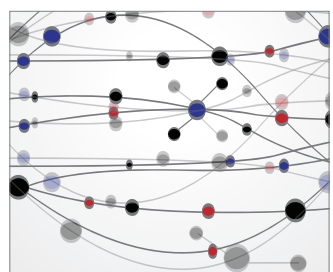

\section{The Scientific} World Journal
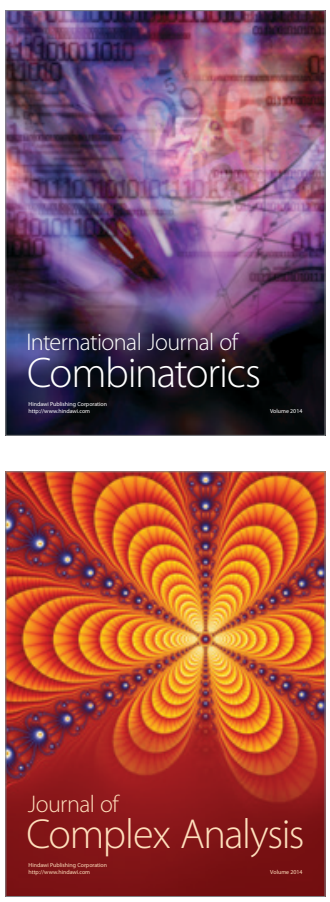

International Journal of

Mathematics and

Mathematical

Sciences
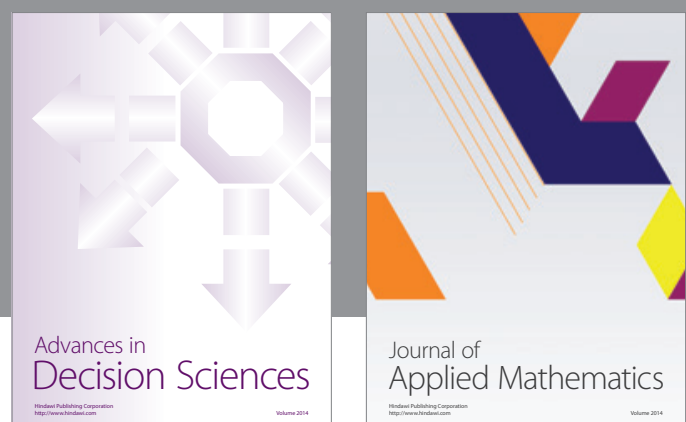

Journal of

Applied Mathematics
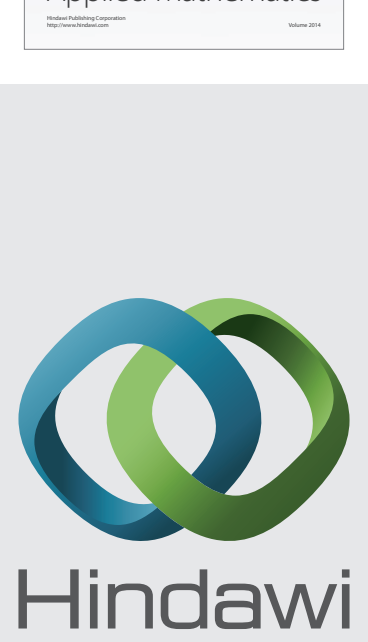

Submit your manuscripts at http://www.hindawi.com
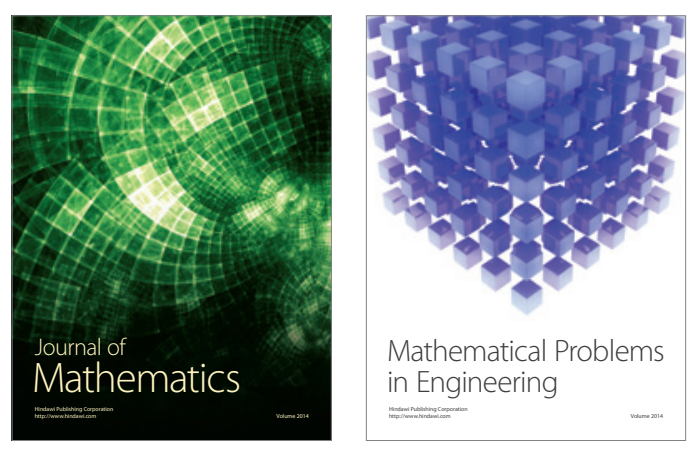

Mathematical Problems in Engineering
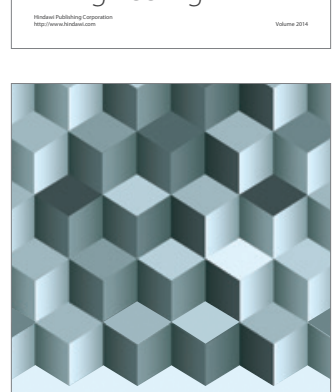

Journal of

Function Spaces
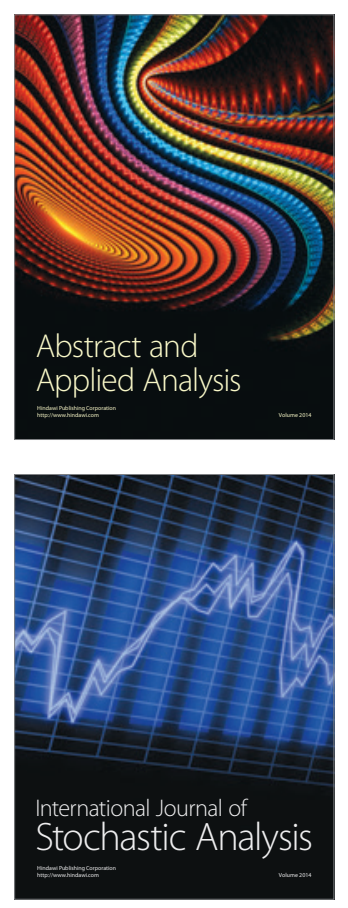

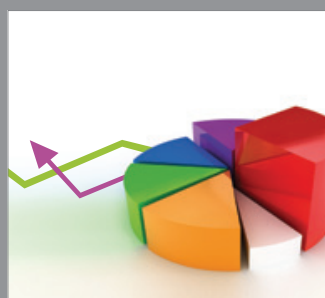

ournal of

Probability and Statistics

Promensencen
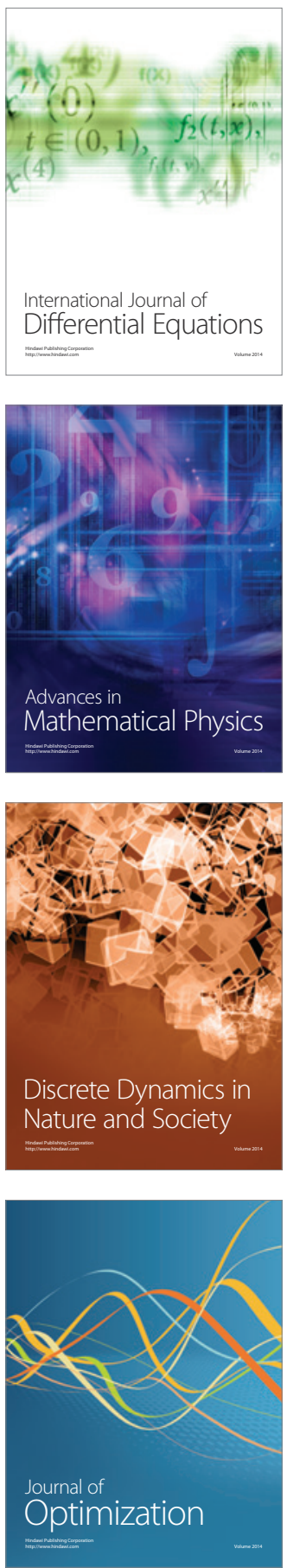